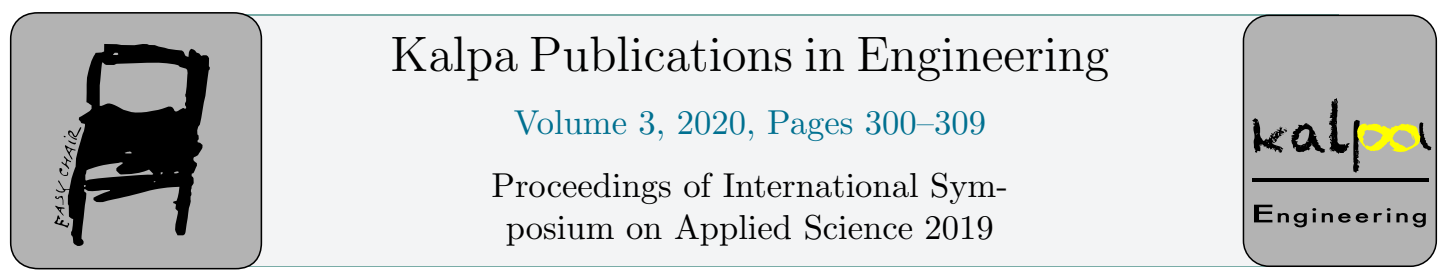

\title{
Optimization in Operating for Linking Reservoirs at Sesan Cascade in the Highland Of Vietnam
}

\author{
Thu Phuong Phan Thi ${ }^{1, *}$ and Tien Cuong Nguyen ${ }^{2,3, \dagger}$ \\ ${ }^{1}$ National University of Civil Engineering \\ ${ }^{2}$ Faculty of Vehicle and Energy Engineering, Phenikaa University \\ ${ }^{3}$ Phenikaa Research and Technology Institute (PRATI) \\ phuongpti@nuce.edu.vn and cuong.nguyentien@phenikaa-uni.edu.vn
}

\begin{abstract}
Differential Evolution and Dynamic Programming are used in reservoir regulation in many research. In the previous works, we presented the outline of Differential Evolution and Dynamic Programming and separately applied them into Pleikrong reservoir and Ialy reservoir, two biggest ones in the Highland of Vietnam for dry season of 2010 and 2012. Continuing from that, in this work, we apply these methods to these two reservoirs at the same time as a multi-reservoir system to reach optimal regulation for the maximum power production.
\end{abstract}

Keywords: DP, DE, Reservoirs, Optimization, Pleikrong Reservoir, Ialy Reservoir.

\section{Introduction}

Nowadays, the demand for electricity is increasing. Hydro-electricity plays an important role in the electricity system of Vietnam. However, the amount of water is decreasing. The problem of for Vietnam and many other countries in the world is how to use the water effectively to meet the demand of electricity but still stay friendly to the environment.

In hydro-power, dams are built and water is kept in the reservoirs then it would be used for several purposes at the same time such as: flood prevention, power generation, irrigation, water transport, and water supply for downstream (Nguyen Tien Cuong, 2008), (H. Van Lai, 2009). However, these tasks often conflict to each other. For example: in the rainy season, the amount of water is high, it is necessary to prevent flooding but too much water can break down the dams; in the dry season, downstream needs more water for irrigation but it is also need to keep water for the output of the

\footnotetext{
${ }^{*}$ Corresponding author at National University of Civil Engineering, Hanoi, Vietnam.

${ }^{\dagger}$ Corresponding author at Phenikaa University, Hanoi, Vietnam.
} 
power stations. That is why the power stations need to be operated optimally and reservoir optimization problem is a significant practice problem in the world and Vietnam in particular.

Depending on specific project characteristics and the amount of incoming water, each reservoir has a priority target that follows specific standards and constraints. Therefore, the optimal problem statement for different reservoir is different, there cannot be a general formula for all.

Multi-reservoir regulation problem has been implemented in many parts of the world (Nadalal, 1995). In Vietnam, there are few research about this problem (N. The Hung, 2011), (Hung, 2012). The optimal problem for reservoirs in Sesan cascade was also study to optimize the electricity by linear programming (Tien, 2006). In this report, we would like to introduce the problem of regulating hydropower reservoirs in case of linking two biggest reservoirs of Sesan cascade: Pleikrong and Ialy, by Dynamic Programming and Differential Evolution - a genetic algorithm. The total output of the two reservoirs is calculated with three different scenarios and the results are compared.

\section{Subjects, Problems and Methods}

\subsection{Subjects}

There are several hydropower plants which are linking together in Sesan cascade: Pleikrong, Ialy, Sesan 3, Sesan 3A, Sesan 4. As we can see, these reservoirs are closely linked to each other. The outputs (releases) of this reservoir are the inputs of the next one. Pleikrong is the first one in the ladder of the reservoirs. It comes from Prong Poko river. Ialy is the second one and has two inflows: from Dak Bla river and from the outputs (releases) of Pleifrong reservoir. Pleikrong and Ialy, which are two biggest constructions in this reservoir ladder, are the subjects of this study.

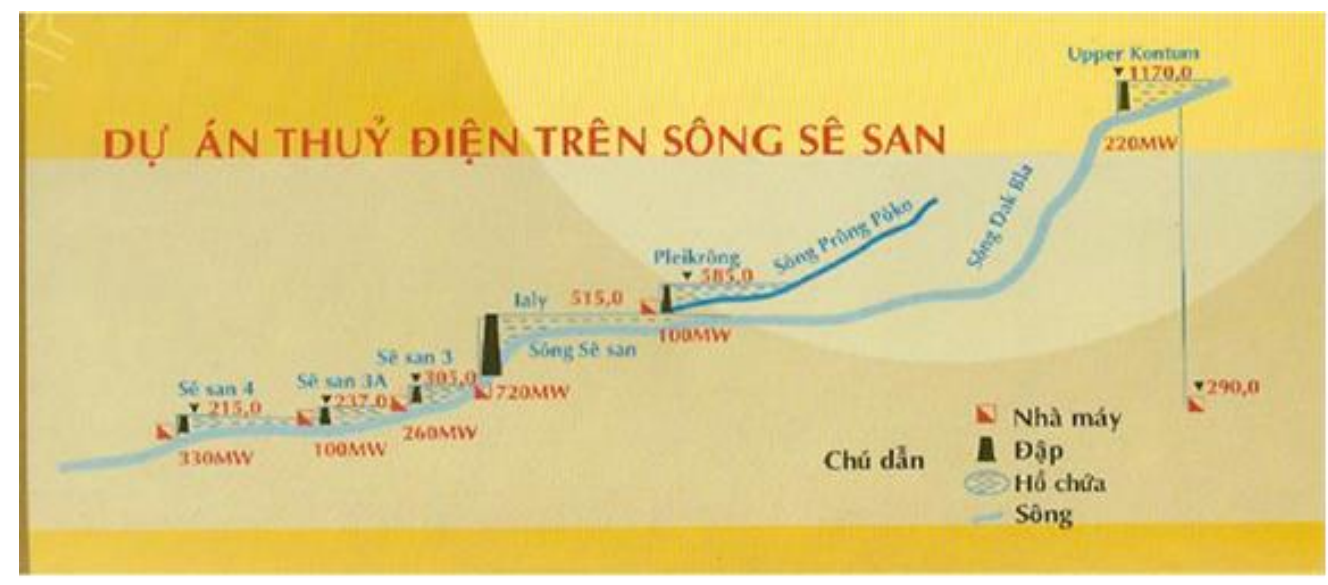

Figure 1: Diagram of hydropower plants in Sesan cascade (Ialy, 2003)

Figure 1: Diagram of hydropower plants in Sesan cascade (Ialy, 2003) shows the position, also the wattages and the normal water levels of the reservoirs (or power plants) in the ladder.

The hydropower system can be described as in Figure 2: Diagram of calculating scope below: 


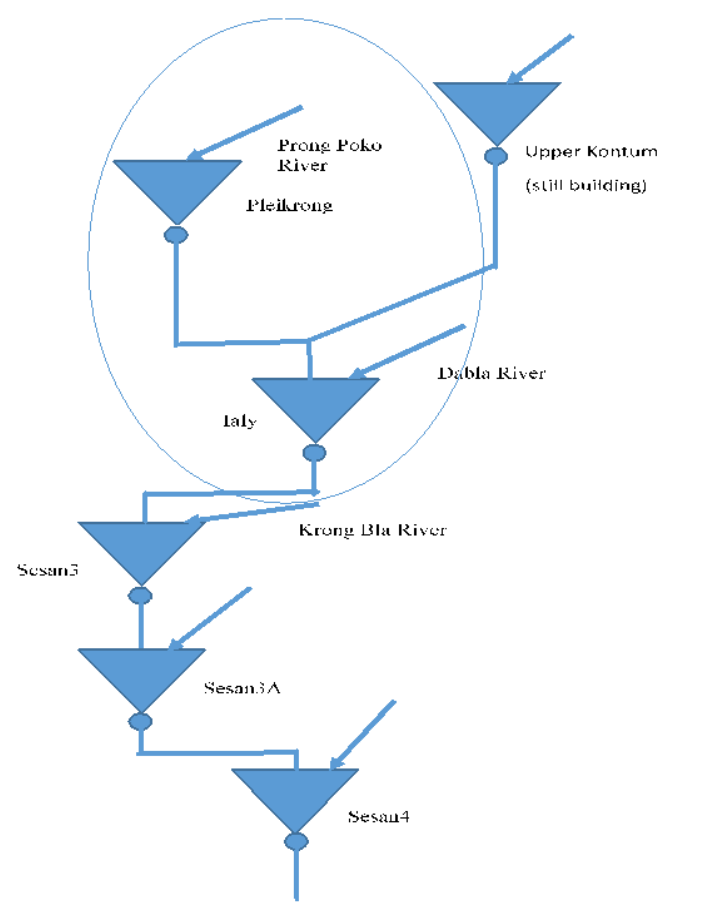

Figure 2: Diagram of calculating scope

In this study, we are concerned about two biggest reservoirs in the ladder which are Pleikrong and Ialy. These two reservoirs have the main role in the electricity system of the area.

\subsection{Problem}

The problem in this study is set as bellow:

Finding the optimal set of releases to get the maximum of total electricity production from both reservoirs Pleikrong and Ialy in dry season of 2010. The calculating time is 140 days that we separate into 14 periods, each period is 10 days (followed by The decision in operation rules for reservoirs in Sesan cascade, No. 1182 QD-TTg of the Government of Vietnam signed in July 17, 2014) (The decision in operation rules for reservoirs in Sesan Cascade, No. 1182 QD-TTg of the Government of Vietnam, 2014)

The objective function in this case is:

Where:

$$
\mathrm{E}=\text { Maximum } \Sigma \mathrm{Ej} \quad(\mathrm{j}=1, \ldots, \mathrm{T})
$$

$$
E_{i}=9.8 * h_{i} * Q_{i} * k * 24 * 10 / 1000(M W h)
$$

$\mathrm{Ei}$ - electricity of period $\mathrm{i}$

hi - water height at time period i,

qi - release at time period i,

$\mathrm{k}$ - overall generation efficiency

Using inputs that are already given in 2010 , we set 3 scenarios:

Pleikrong reservoir is using real operation, only optimize the operation of Ialy reservoir.

Optimize the operation of Pleikrong reservoir only, Ialy reservoir is real operated

Optimize both reservoirs at the same time 
Then we compare the total electricity power of two reservoirs to find out which scenario gives the highest amount of electricity power.

\subsection{Methods}

We use two methods to solve this problem:

\subsubsection{Dynamic Programming}

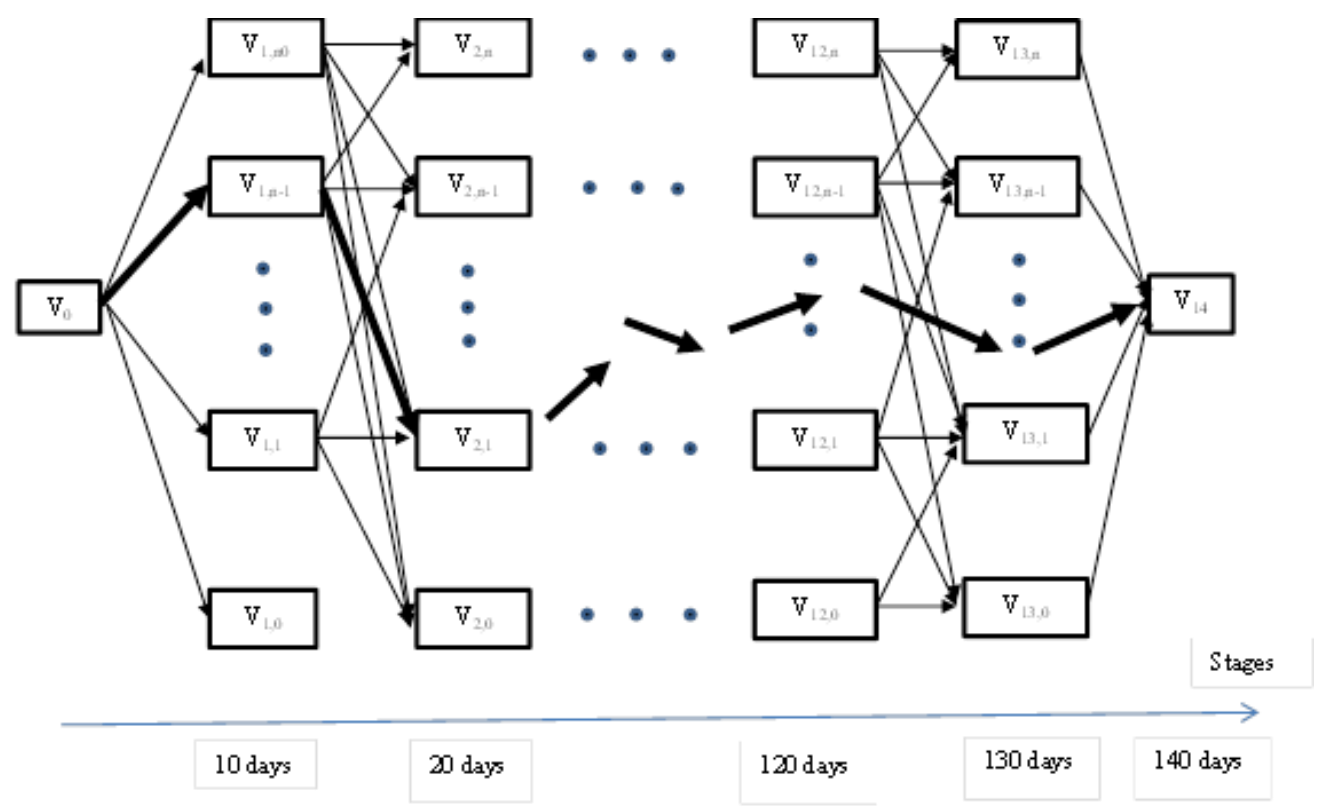

Figure 3: Chart of Dynamic programming (Phuong P.T.T H. D., 2017)

There are 14 periods now called 14 stages.

The maximum electricity power of all 14 stages is the sum of the electricity from each stage by the optimal way.

From the initial volume, we calculate all possible options of releases that satisfy the structure design and the inputs, then calculate the electricity corresponding to them. The releases give the highest electricity is the optimal set of releases to operate in the stage.

In the next stages, the initial volume is the volume of the reservoir after the previous stage and the inflow from the upper stream.

\subsubsection{Differential Evolution}

Differential Evolution is a branch of Genetic algorithm.

In this method, we use the real operation as the initial solution:

$$
x_{0}=\left(x_{01}, x_{02}, \ldots, x_{0 n}\right)^{T} \quad n=14
$$

Then we create the solution of the next step by adding a weighted differences between the given solutions to each value of the solution

$$
V_{i}^{(G+1)}=X_{r 1}^{(G)}+F\left[X_{r 2}^{(G)}-X_{r 3}^{(G)}\right]
$$


F $>0$ is a real random parameter, called mutant constant, which controls the difference between two individuals, used to avoid the slow searching.

This step is called mutant

$\mathrm{r} 1, \mathrm{r} 2, \mathrm{r} 3$ are random integers chosen from 1 to NP.

After the mutant step, we calculate the electricity by new solution. If the electricity by the new solution is higher than the previous one then it is kept for the next step.

The loop will be repeated until the optimization of the problem has been reached.

\subsubsection{Inputs}

The data that is used in this paper was provided by the team of Institute of Mechanics of VAST in project of building the reservoir operation for Sesan cascade in dry season (process of multi-reservoir operation on the Sesan river basin of the Prime Minister, 2014).

In Table 1: Input of Pleikrong reservoir and Ialy reservoir in 2010 and 2012 and Table 2: Inflow of Pleikrong reservoir and to Ialy reservoir from DakBla river in the year 2010, the design parameters of Pleikrong and Ialy power plants are given. These parameters are used as the inputs and the constraints of the problem.

\begin{tabular}{|l|r|r|}
\hline & Plei2010 & Ialy 2010 \\
\hline Total volume $\left(\times 10^{6} \mathrm{~m}^{3}\right)$ & $1.048,691300$ & 1037000000 \\
\hline Useful volume $\left(\times 10^{6} \mathrm{~m}^{3}\right)$ & 948,430000 & 779,000000 \\
\hline Normal water level $(\mathrm{m})$ & 570 & 512 \\
\hline Turbine water level $(\mathrm{m})$ & 514 & 304 \\
\hline Death storage $\left(\mathrm{x} 10^{6} \mathrm{~m}^{3}\right)$ & 100,261300 & 263,830000 \\
\hline Death water level $(\mathrm{m})$ & 537,000000 & 490,000000 \\
\hline Initial volume $\left(\mathrm{x} 10^{6} \mathrm{~m}^{3}\right)$ & $1.096,894100$ & 396,939548 \\
\hline Initial storage $\left(\mathrm{x} 10^{6} \mathrm{~m}^{3}\right)$ & 996,632800 & 660,769548 \\
\hline Initial water level $(\mathrm{m})$ & 569,000000 & 506,590000 \\
\hline Maximum release $\left(\mathrm{m}^{3} / \mathrm{s}\right)$ & 330,000000 & 420,000000 \\
\hline Overall generation efficiency & 0,898869 & 0,900125 \\
\hline
\end{tabular}

Table 1: Input of Pleikrong reservoir and Ialy reservoir in 2010 and 2012

\begin{tabular}{|c|c|c|c|}
\hline $\begin{array}{c}\text { N0 } \\
\text { period }\end{array}$ & Time of period & $\begin{array}{c}\text { Inflow to Pleikrong } \\
\text { reservoir }\left(\mathrm{m}^{3} / \mathrm{s}\right) \text { in 2010 }\end{array}$ & $\begin{array}{c}\text { Inflow to Ialy reservoir } \\
\text { from DakBla river 2010 }\end{array}$ \\
\hline 1 & 11/Feb-20/Feb & 47.73 & 52.43 \\
\hline 2 & 21/Feb-02/Mar & 53.35 & 41.9 \\
\hline 3 & 03/Mar-12/Mar & 23.79 & 49.63 \\
\hline 4 & 13/Mar-22/Mar & 51.8 & 37.25 \\
\hline
\end{tabular}




\begin{tabular}{|c|c|c|c|}
\hline 5 & 23/Mar-01/Apr & 31.98 & 26.98 \\
\hline 6 & 02/Apr-11/Apr & 10.86 & 41.55 \\
\hline 7 & 12/Apr-21/Apr & 44.56 & 46.58 \\
\hline 8 & 22/Apr-01/May & 41.18 & 46.2 \\
\hline 9 & 02/May-11/May & 14.54 & 60.05 \\
\hline 10 & 12/May-21/May & 23.54 & 42.28 \\
\hline 11 & 22/May-31/May & 0.09 & 43.08 \\
\hline 12 & 01/Jun-10/Jun & 17.15 & 56.55 \\
\hline 13 & 11/Jun-20/Jun & 44.76 & 41.25 \\
\hline 14 & 21/Jun-30/Jun & 36.48 & 43.43 \\
\hline
\end{tabular}

Table 2: Inflow of Pleikrong reservoir and to Ialy reservoir from DakBla river in the year 2010

\section{Results And Discussion}

\subsection{Results}

We calculate the total electrical production of two reservoirs in 2010 in three scenerios:

1. Pleikrong is using real operation, only optimize the operation of Ialy.

2. Optimize the operation of Pleikrong reservoir only, Ialy reservoir is real operated.

3. Optimize both reservoirs at the same time.

The solutions of scenario 1, which is optimize the operation of Ialy reservoir by two methods, are shown in the Table 3: Optimal releases of Ialy reservoir by DP and DE in 2010 in scenario 1 (Using real operation of Pleikong)

The solutions of scenario 2, which is optimize the operation of Pleikrong reservoir using Dynamic Program and Differential Evolution, are shown in the Table 4: Optimal releases of Pleikrong reservoir by DP and DE in 2010 in scenario 2 (using real operation of Ialy)

Table 5: Optimal releases of two reservoir Pleikrong and Ialy at the same time by in 2010 in scenario shows the solutions of scenario 3 , which is optimize both reservoirs at the same time.

\begin{tabular}{|c|c|c|c|}
\hline $\begin{array}{c}\text { N0 } \\
\text { period }\end{array}$ & Time of period & $\begin{array}{c}\text { Optimal releases of Ialy } \\
\text { reservoir by DP }\left(\mathrm{m}^{3} / \mathrm{s}\right)\end{array}$ & $\begin{array}{c}\text { Optimal releases of Ialy } \\
\text { reservoir by DE }\left(\mathrm{m}^{3} / \mathrm{s}\right)\end{array}$ \\
\hline 1 & 11/Feb-20/Feb & 8.386377 & 0 \\
\hline 2 & 21/Feb-02/Mar & 0.384566 & 0 \\
\hline 3 & 03/Mar-12/Mar & 58.12228 & 72.479129904 \\
\hline 4 & 13/Mar-22/Mar & 126.35 & 101.31 \\
\hline 5 & 23/Mar-01/Apr & 189.48 & 188.70 \\
\hline 6 & 02/Apr-11/Apr & 248.25 & 236.27 \\
\hline
\end{tabular}




\begin{tabular}{|c|c|c|c|}
\hline 7 & 12/Apr-21/Apr & 215.98 & 223.31 \\
\hline 8 & 22/Apr-01/May & 169.2 & 165.54 \\
\hline 9 & 02/May-11/May & 223.25 & 238.79 \\
\hline 10 & 12/May-21/May & 188.08 & 134.46 \\
\hline 11 & 22/May-31/May & 124.88 & 118.99 \\
\hline 12 & 01/Jun-10/Jun & 179.3757 & 163.57164806 \\
\hline 13 & 11/Jun-20/Jun & 418.9286 & 420 \\
\hline 14 & 21/Jun-30/Jun & 410.7174 & 420 \\
\hline & Electrical production & $\mathbf{1 , 1 0 7 , 9 0 1 . 5 5} \mathbf{M W h}$ & $\mathbf{1 , 0 8 1 , 2 3 4 . 9 9 ~} \mathbf{M W h}$ \\
\hline & Real electrical production & $\mathbf{1 , 0 6 3 , 9 4 8} \mathbf{M W h}$ & \\
\hline
\end{tabular}

Table 3: Optimal releases of Ialy reservoir by DP and DE in 2010 in scenario 1 (Using real operation of Pleikong)

\begin{tabular}{|c|c|c|c|}
\hline N0 period & Time of period & $\begin{array}{c}\text { Optimal releases } \\
\text { of Pleikrong reservoir } \\
\text { by DP }\left(\mathrm{m}^{3} / \mathrm{s}\right)\end{array}$ & $\begin{array}{l}\text { Optimal releases of } \\
\text { Pleikrong reservoir } \\
\text { by DE }\left(\mathrm{m}^{3} / \mathrm{s}\right)\end{array}$ \\
\hline 1 & 11/Feb-20/Feb & 2.540329861 & 0.0 \\
\hline 2 & 21/Feb-02/Mar & 38.28677662 & 40.53416590 \\
\hline 3 & 03/Mar-12/Mar & 23.79 & 23.78999995 \\
\hline 4 & 13/Mar-22/Mar & 51.8 & 51.80000037 \\
\hline 5 & 23/Mar-01/Apr & 31.98 & 31.98000024 \\
\hline 6 & 02/Apr-11/Apr & 10.86 & 10.86000043 \\
\hline 7 & 12/Apr-21/Apr & 44.56 & 44.56000130 \\
\hline 8 & 22/Apr-01/May & 41.18 & 41.17999976 \\
\hline 9 & 02/May-11/May & 14.54 & 14.53999904 \\
\hline 10 & 12/May-21/May & 23.54 & 83.22103829 \\
\hline 11 & 22/May-31/May & 228.1684399 & 199.33007812 \\
\hline 12 & 01/Jun-10/Jun & 322.287357 & 277.37941453 \\
\hline 13 & 11/Jun-20/Jun & 319.3836213 & 329.80134326 \\
\hline 14 & 21/Jun-30/Jun & 326.3604892 & 329.97833269 \\
\hline
\end{tabular}




\begin{tabular}{|l|c|c|c|}
\hline & $\begin{array}{c}\text { Electrical } \\
\text { production }\end{array}$ & $\mathbf{1 4 1 , 0 6 0 . 5 9}$ MWh & $\mathbf{1 4 1 , 0 7 9 . 0 8}$ MWh \\
\hline & $\begin{array}{c}\text { Real electrical } \\
\text { production }\end{array}$ & $\mathbf{1 3 3 , 5 4 7}$ MWh & \\
\hline
\end{tabular}

Table 4: Optimal releases of Pleikrong reservoir by DP and DE in 2010 in scenario 2 (using real operation of Ialy)

\begin{tabular}{|c|c|c|c|}
\hline N0 period & Time of period & $\begin{array}{c}\text { Optimal releases } \\
\text { of Pleikrong reservoir }\left(\mathrm{m}^{3} / \mathrm{s}\right)\end{array}$ & $\begin{array}{c}\text { Optimal releases of } \\
\text { Ialy reservoir }\left(\mathrm{m}^{3} / \mathrm{s}\right)\end{array}$ \\
\hline 1 & 11/Feb-20/Feb & 62.6 & 0 \\
\hline 2 & 21/Feb-02/Mar & 84.1 & 19.4 \\
\hline 3 & 03/Mar-12/Mar & 0 & 63.2 \\
\hline 4 & 13/Mar-22/Mar & 106 & 137 \\
\hline 5 & 23/Mar-01/Apr & 72.5 & 37.5 \\
\hline 6 & 02/Apr-11/Apr & 212 & 241 \\
\hline 7 & 12/Apr-21/Apr & 0 & 53.9 \\
\hline 8 & 22/Apr-01/May & 122 & 163 \\
\hline 9 & 02/May-11/May & 284 & 360 \\
\hline 10 & 12/May-21/May & 226 & 215 \\
\hline 11 & 22/May-31/May & 188 & 171 \\
\hline 12 & 01/Jun-10/Jun & 41.1 & 382 \\
\hline 13 & 11/Jun-20/Jun & 44.8 & 420 \\
\hline 14 & 21/Jun-30/Jun & 36.5 & $\mathbf{1 , 0 7 2 , 5 4 4 . 7 1 ~ M W h ~}$ \\
\hline & Electrical production & $\mathbf{1 8 8 , 5 0 3 . 6 3} \mathbf{M W h}$ & \\
\hline
\end{tabular}

Table 5: Optimal releases of two reservoir Pleikrong and Ialy at the same time by in 2010 in scenario

We have the total electrical production of two reservoirs in 2010 in three scenarios shown in Table 6: Electricity production of two reservoirs in 2010 by 3 scenarios and in chart forms as Figure 4: Total electricity of Pleikrong and Ialy in 2010 as following:

\begin{tabular}{|c|c|c|l|}
\hline Scenerio & $\begin{array}{c}\text { Electricity } \\
\text { production of Pleikrong }\end{array}$ & $\begin{array}{c}\text { Electricity } \\
\text { production of Ialy }\end{array}$ & \multicolumn{1}{|c|}{ Sum } \\
\hline Real operation & $133,547 \mathrm{MWh}$ & $1,063,948 \mathrm{MWh}$ & $\mathbf{1 , 1 9 7 , 4 9 5} \mathbf{M W h}$ \\
\hline 1 & $133,547 \mathrm{MWh}$ & $1,081,234.99 \mathrm{MWh}$ & $\mathbf{1 , 2 1 4 , 7 8 1 . 9 9} \mathbf{M W h}$ \\
\hline
\end{tabular}




\begin{tabular}{|l|l|l|l|}
\hline 2 & $141,079.0869 \mathrm{MWh}$ & $1,063,948 \mathrm{MWh}$ & $\mathbf{1 , 2 0 5 , 0 6 3 . 0 9} \mathbf{M W h}$ \\
\hline 3 & $188,503.63 \mathrm{MWh}$ & $1,072,544.71 \mathrm{MWh}$ & $\mathbf{1 , 2 6 1 , 0 4 8 . 3 4} \mathbf{M W h}$ \\
\hline
\end{tabular}

Table 6: Electricity production of two reservoirs in 2010 by 3 scenarios

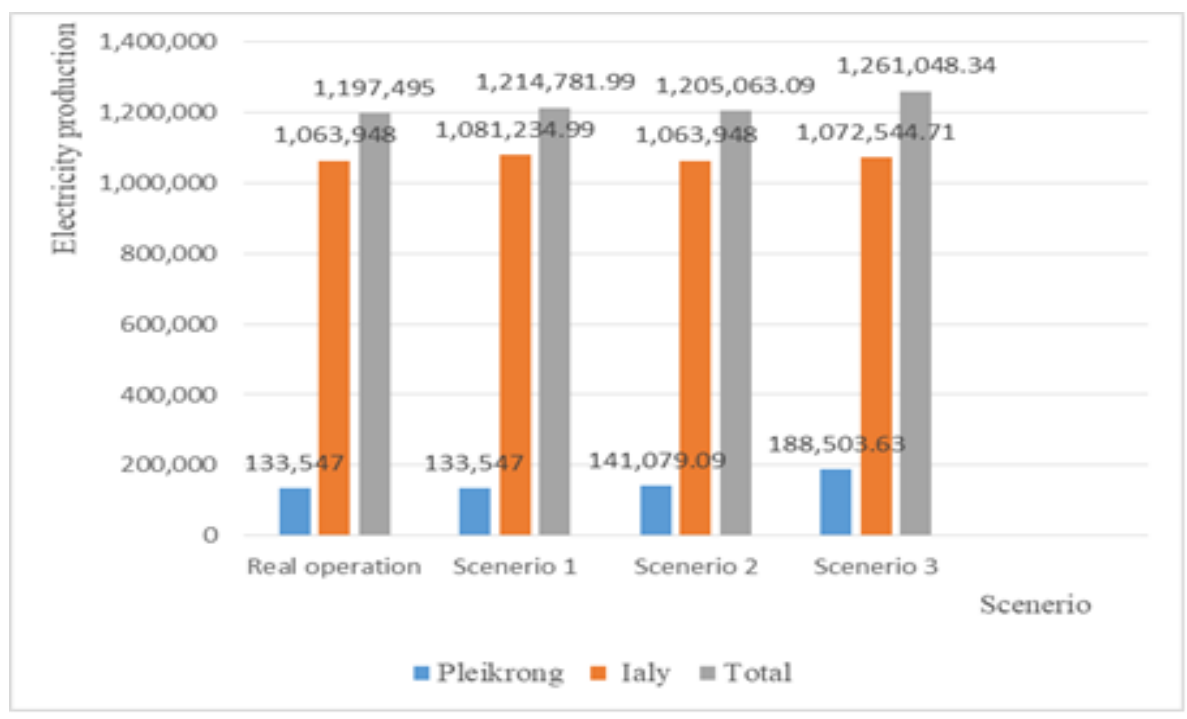

Figure 4: Total electricity of Pleikrong and Ialy in 2010

\subsection{Discussion}

As we can see in Table 3: Optimal releases of Ialy reservoir by DP and DE in 2010 in scenario 1 (Using real operation of Pleikong), Table 4: Optimal releases of Pleikrong reservoir by DP and DE in 2010 in scenario 2 (using real operation of Ialy) and Table 5: Optimal releases of two reservoir Pleikrong and Ialy at the same time by in 2010 in scenario, the trend of operation to reach maximum power electricity is storing the water at the beginning then giving massive discharges at the end of the calculation time.

From Table 6: Electricity production of two reservoirs in 2010 by 3 scenarios and Figure 4: Total electricity of Pleikrong and Ialy in 2010, the total electricity from Ialy reservoir in 2010 is nearly ten times bigger than Pleikrong reservoir and optimizing both reservoir at the same time gives the highest electricity production in three scenarios.

\section{Conclusions}

The present study shows that water releases are depended on the inflows to the reservoirs. To reach the maximum electricity production, it needs to keep the water then increases the releases at the end of the season. In three scenarios, the main electricity of these two reservoirs is from Ialy. It is nearly 10 times of the electricity from Pleikrong reservoir. The scenario which optimizes both reservoirs at the same time give the highest amount of electricity production. 


\section{Acknowledgements}

This research is funded by Vietnam National Foundation for Science and Technology Development (NAFOSTED) under grant number 107.03-2017.12.

\section{References}

The decision in operation rules for reservoirs in Sesan Cascade, No. 1182 QD-TTg of the Government of Vietnam . (2014, july 17).

Bellman, R. (1957). Dynamic Programming, Princeton. NJ: Princeton University Press.

Chow, V. t. (1971). Methodology for water resources planning: DDDP and MLOM. Water Resources Research, University of Illinois.

H. Van Lai, N. V. (2009). Coupling hydrological-hydraulic models for extreme flood simulating and forecasting on the North Central Coast of Vietnam. WIT Transctions on Ecology and the Environment, Vol.124, 113-123.

Heidar, M. C. (1971). Discrete differential dynamic programming approach to water resources systems optimizations. Water Resources Research, 7, 273-282.

Hung, L. (2012). Multi-objective Reservoirs Optimizationa. PhD Thesis, Danang University.

Labadie, J. (2003). Generalized Dynamic Programming Package: CSUDP-Documentation and User Guide. Colorado State University .

Labadie, J. (2004). Optimal Operation of Multireservoir Systems: State-of-the-Art Review. Journal of Water Resources Planning and Management, 93-111.

N. The Hung, L. H. (2011). An Optimal Regulation mathematical model for multipurpose reservoir operation (For the purpose of irrigation, flood control, hydropower generation, environmental preservation or downstream water supply). Magazine of Science and Technology, University of Danang 2 (43), 35-43.

Nadalal, K. (1995). Reservoir management under consideration of stratification and hydraulic phenomena. Ph.D Dissertation, Department of Water Resources, Wageningen Agricultural University, the Netherlands.

Nguyen Tien Cuong, T. T. (2008). Forecasting the discharge into Hoa Binh reservoir by applying the Connecting model MARINE-IMECH 1D. Vietnam Journal of Mechanics, VAST (3), 149157.

Cuong T Nguyen, Kien C Nguyen, Phuong TT Phan (2018). Hydrological-Quasi 2D Hydraulic Linked Model for Flood Forecasting. American Journal of Engineering Research, Vol. 7 (10), 325-331.

Cuong T. Nguyen, Kien C. Nguyen (2018). Research and Proposal a Solution to Mitigate Salinity Intrusion for Tam Ky River in Quang-Nam Province of Vietnam. International Journal of Scientific Engineering and Applied Science. Vol. 3 (11), 13-18

Phuong P.T.T, H. D. (2017). Reservoir optimization with Dynamic programming. Vietnam Journal of Mechanics, VAST, 39 (2), 191-202.

Phuong P.T.T, L. H. (2016). Reservoir optimization by Differential Evolution. Vietnam Journal of Mechanics, 38 (1), 39-48.

Tien, C. D. (2006). Optimal operation for ladder of hydro-power plants in Sesan cascade. Master thesis, HCM University of Technology, 55. 